\title{
Espaço para profissional de saúde versus Intersubjetividade: relato de experiência
}

RESUMO | Trata-se de relato de experiência sobre minicurso ministrado no âmbito do I Congresso de Condições Crônicas Pediátricas do IFF/FIOCRUZ que teve como foco principal promover um espaço de reflexão junto à profissionais de saúde sobre aspectos intersubjetivos do cuidar no ambiente hospitalar. O formato de metodologia ativa foi adotado por permitir maior momento de trocas. Sobre as experiências compartilhadas, os relatos foram majoritariamente relativos ao sofrimento e à morte de crianças.

Palavras-chaves: Cursos; Pessoal de Saúde; Comunicação; Relações Interpessoais.

ABSTRACT | This is an experience report on a mini course given in the context of the I Congress of Chronic Pediatric Conditions of the IFF/FIOCRUZ, whose main focus was to promote a space for reflection with health professionals on intersubjective aspects of care in the hospital environment. The active methodology format was adopted because it allows for a greater exchange moment. About the shared experiences, the reports were mostly related to the suffering and death of children.

Keywords: Courses; Health Personnel; Communication; Interpersonal Relations.

RESUMEN | Este es un informe de experiencia sobre un mini curso impartido en el marco del I Congreso de Condiciones Pediátricas Crónicas del IFF/FIOCRUZ que tuvo como foco principal promover un espacio de reflexión con profesionales de la salud sobre aspectos intersubjetivos de la atención en el entorno hospitalario. Se adoptó el formato de metodología activa porque permite un mayor momento de intercambio. Sobre las experiencias compartidas, los informes se relacionaron principalmente con el sufrimiento y la muerte de los niños.

Palavras claves: Cursos; Personal Sanitario; Comunicación; Relaciones Interpersonales.

\section{Rosilene Aparecida dos Santos}

Enfermeira. Doutoranda e Mestre em Saúde da Mulher e da Criança (Saúde Coletiva) pelo Instituto Nacional da Saúde da Mulher, da Criança e do Adolescente Fernandes Figueira da Fundação Oswaldo Cruz (IFF/Fiocruz). Técnica em Saúde Pública do IFF/Fiocruz.

\section{Giselle Barcellos Oliveira Koeppe}

Enfermeira. Mestre e Doutora em Enfermagem. Técnica em Saúde Pública do Instituto Nacional de Saúde da Mulher, da Criança e do Adolescente Fernandes Figueira da Fundação Oswaldo Cruz (IFF/ FIOCRUZ).

\section{Mariana Setúbal Nassar de Carvalho}

Assistente Social. Doutora em Serviço Social. Tecnologista em Saúde Pública do Instituto Nacional de Saúde da Mulher, da Criança e do Adolescente Fernandes Figueira da Fundação Oswaldo Cruz (IFF/ Fiocruz).

Recebido em: 08/05/2020

Aprovado em: 08/05/2020

INTRODUÇÃo

$\Lambda$ intersubjetividade configura uma condição da vida social que permite o compartilhamento de sentidos, experiências e conhecimentos entre os sujeitos. Ela engloba três importantes pilares, representados pelas dimensões do afeto, da defesa de direitos e da estima social, que precisam ser consideradas nas relações estabelecidas ${ }^{(1)}$.

A valorização dos processos intersubjetivos presentes no campo da gestão e do cuidado em saúde é um pilar fundamental para o que se denomina como "trabalho vivo em ato", nos termos de Mehry ${ }^{(2: 45)}$, composto por artesania de saberes teóricos e práticos.

Esta produção do cuidado requer valorização das singularidades dos atores envolvidos, convergindo ciência, técnicas e relações. A compreensão do contexto de vida, interpretações e sentidos das pessoas que integram as equipes de trabalho (sobre si e sobre o outro), auxilia na potencialização das tecnologias relacionais, por funcionar como mola propulsora de um trabalho com propósito, motivação e significado. Dar luz à subjetividade nesse campo significa ampliar a lógica da superespecialização da saúde e a hegemonia biomédica. Não queremos com isso negar a dimensão biológica e o conhecimento técnico-científico no processo de cuidar, mas relativizá-lo a partir do que Foucault chama a atenção como sendo uma tecnologia de poder sobre os $\operatorname{corpos}^{(3)}$. Consideramos, portanto, que a subjetividade e a intersubjetividade estão essencialmente na cena no cotidiano profissional em saúde( ${ }^{(4)}$, a fim de promover ações pautadas em experiências de relação interpessoal, valorizando uma relação de proximidade dialógica entre quem cuida e quem é cuidado(5).

Neste contexto, é de fundamental importância que os profissionais de saúde tenham um espaço para discussão dos aspectos intersubjetivos de seu cotidiano de trabalho. Tais discussões representam uma base para a conexão de ideias que produzam interações construídas na valorização da troca de percepções e experiências entre os sujeitos envolvidos.

$\mathrm{O}$ ato de compartilhar vivências e saberes pode ser um elemento de contribuição para que a equipe de saúde possa repensar a prática assistencial para além de um saber eminentemente técnico. Nesta configuração é possível que sentimentos, 
atitudes, cooperação, solidariedade e responsabilidade social sejam discutidos em um mesmo contexto, sendo colocados como elementos indispensáveis à atividade profissional ${ }^{(6)}$.

Diante do exposto, este estudo tem por objetivo relatar a experiência de enfermeiras na ministração de um minicurso interdisciplinar com foco na discussão da intersubjetividade no processo de cuidar. A questão que norteou o estudo foi: De que forma um minicurso interdisciplinar pode representar um espaço de discussão acerca da intersubjetividade no processo de cuidado em saúde?

\section{METODOLOGIA}

Trata-se de relato de experiência sobre a realização de minicurso ministrado por duas enfermeiras intitulado "Intersubjetividade no ambiente hospitalar: reflexões sobre o cuidar", que fez parte da programação do I Congresso de Condições Crônicas Pediátricas do IFF/VPAAPS/FIOCRUZ, em setembro de 2019, e teve como foco principal promover um espaço de reflexão junto à profissionais de saúde sobre aspectos intersubjetivos do cuidar.

\section{RELATO DA EXPERIÊNCIA}

A ementa incluiu elementos, como: conceito de subjetividade e a mesma como centro do cuidado em saúde; hegemonia biomédica e limitações no processo de cuidado; intersubjetividade e cuidado hospitalar; usuários com necessidades especiais e subjetividade.

Nossos principais propósitos discutiam sobre a construção de relações interpessoais entre usuários e profissionais de saúde na internação hospitalar; sobre possíveis embotamentos no espaço de cuidado que podem derivar da hegemonia biomédica; da importância da integração entre a gestão e equipes para a efetividade do trabalho; das especificidades da clientela com limitações na comunicação e expressão na compreensão da subjetividade; e o compartilhamento de experiências da assistência, que despertaram sentimentos e reflexões que contribuíram pra a mudança na sua prática assistencial.

O minicurso ocorreu em 23 de setembro de 2019, sob a coordenação e ministração de duas enfermeiras atuantes na enfermaria de pediatria do Instituto Nacional de Saúde da Mulher, da Criança e do Adolescente Fernandes Figueira/ Fiocruz (IFF/FIOCRUZ), com duração de 4 horas. Teve total de 12 participantes, divididos entre enfermeiros, técnicos de enfermagem, acadêmicos de enfermagem e psicólogos. O número reduzido de integrantes ocorreu de forma intencional para se tornar possível a partilha de conhecimentos e experiências de forma satisfatória, onde todos pudessem ter a oportunidade de se expressar. A maioria dos participantes era da própria instituição e atuava na assistência pediátrica. A sala foi organizada com as cadeiras ordenadas em círculo para maior contato olho no olho e melhor comunicação. Foi disposta uma mesa com café da manhã como forma de promover acolhimento e estreitar a interação. Em nenhum momento utilizamos recursos audiovisuais.

A estratégia inicial abrangeu a apresentação das enfermeiras responsáveis, seguida pelos demais participantes, incluindo nome, local de trabalho e motivação para participação. Posteriormente, experiências da prática assistencial foram compartilhadas entre as enfermeiras palestrantes e os demais integrantes do grupo, permitindo uma exposição de situações reais vivenciadas durante o exercício das atividades profissionais. Todo o compartilhamento foi amparado por aportes teóricos referentes à intersubjetividade.

Após rápido intervalo, as discussões seguiram-se pautadas nos assuntos previamente definidos na ementa do minicurso. Ato contínuo, foi solicitado que cada participante relatasse um episódio marcante da sua prática profissional, que envolvesse a subjetividade dele, do outro, ou de ambos. Foi um momento de importante imersão, reflexão e partilha, que aflorou a emoção de todos os envolvidos.

Por fim, os participantes foram indagados sobre dores e conflitos decorrentes da prática assistencial, salientando a existência ou não de suporte por parte da instituição. O minicurso foi encerrado em clima de leveza, descontração e reflexão, sendo sugerida a realização do mesmo em outro cenário, com outros profissionais das equipes.

\section{DISCUSSÃO}

O formato de metodologia ativa adotado no minicurso foi de fundamental importância por permitir um momento de trocas, sem a imposição de um saber detido apenas pelas palestrantes. Buscamos um processo reconstitutivo, onde os participantes pudessem ter uma aprendizagem significativa, sendo motivados a refletirem sobre o problema, examinando-o e ressignificando-o(7). A aplicabilidade da metodologia ativa na prática contribui para o aperfeiçoamento técnico e humanizado de profissionais comprometidos com o bem-estar dos pacientes. Favorece ainda a aquisição de competências para gerir, implementar e liderar resoluções de problemas de saúde comuns no cotidiano de trabalho(8).

Sobre as experiências compartilhadas, como a maior parte dos participantes atua no atendimento pediátrico, os relatos foram majoritariamente relativos ao sofrimento e à morte de crianças. $\mathrm{O}$ "nó na garganta" e as lágrimas durante os depoimentos demonstraram o quanto os fatos foram marcantes para esses profissionais. Houve ainda uma explanação referente a uma experiência com um paciente psiquiátrico, onde o "ouvir" e "entrar" no mundo do outro representou a chave para a conexão com a pessoa e a interpretação do seu "eu".

A maior parte das experiências marcantes compartilhadas fez referência a situações de morte vivenciadas pelos participantes, que descreveram momentos 
divididos com a criança e sua família em situações de intenso sofrimento relacionado ao processo de morte, afirmando a extrema impotência e devastação emocional. Diante das situações descritas, os integrantes assumiram questionamentos acerca da interrupção da vida de forma precoce e do grande sofrimento enfrentado em uma faixa etária em que as pessoas deviam estar brincando, crescendo e se desenvolvendo, e não padecendo.

Os participantes mostraram-se bastante afetados, ainda, pelos comportamentos das famílias, quando estas não possuem condições de garantir a presença durante toda a internação ou nos momentos de finitude da vida. Os questionamentos neste sentido foram pautados em questões da temporalidade, parentalidade e afetos, nesse universo peculiar de internação pediátrica, em especial as prolongadas (consideradas aquelas com mais de trinta dias), levando em consideração ainda a condição social destas famílias.

Toda essa aflição compartilhada acerca do processo de morrer ocorre porque a morte no hospital desconfigura o evento tido por milênios como propriedade natural do homem, transformando-a num evento de domínio institucional, sob uma força de trabalho comprada ${ }^{(12)}$.

A discussão sobre a morte é complexa e na clientela pediátrica se torna mais, talvez por não ser um evento esperado na infância, por parecer "fugir do ciclo natural da vida". A emoção produzida nos profissionais é decorrente da criação de laços afetivos com os pacientes, que são ainda mais reforçados em casos de internação hospitalar longa. Por esta razão, refletir sobre esta temática, buscando compreender a vivência dos profissionais, é de suma importância, pois muitos deles têm dificuldade em lidar com o óbito de crianças sem sofrer, o que a longo prazo pode acarretar patologias ${ }^{(10)}$.

Outro ponto relevante que surgiu no decorrer da atividade foi a possibilidade de diferença na forma de cuidar em pediatria entre as profissionais que são e as que não são mães. Porém, en-

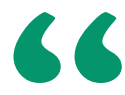

tre as discussões se evidenciou que tal diferenciação não era pertinente para a nossa proposta.

Também foram explanados os conceitos de maternagem, profissionalismo, competência, função de holding (sustentação) e função de containing (continência) e perfis individuais. O aporte teórico de tal discussão foi $\mathrm{Fi}$ gueiredo, que diz que "muitas vezes, cuidar é, basicamente, ser capaz de prestar atenção e reconhecer o objeto dos cuidados no que ele tem de próprio e singular, dando disso testemunho e, se possível, levando de volta ao sujeito sua própria imagem" (11:18).

Os profissionais de saúde, ao cuidarem de bebês e crianças, podem também oferecer segurança física e emocional, sendo importantes peças para as suas elaborações, projeções e ressignificações. Então, as funções de holding e função de containing, que são primordiais na constituição do ser, não precisam necessariamente ser compartilhadas com pais ou profissionais que já sejam pais. É preciso apenas disposição para "estar e ser" (12).

Quanto ao suporte emocional que merecia ser ofertado aos profissionais que atuam em meio a tanto sofrimento, os participantes afirmaram que não recebem tal apoio. Tal informação foi amplamente discutida, sendo avaliado que tal estratégia precisa ser colocada em ação de forma emergencial, visando maior aprimoramento da assistência a partir do equilíbrio da saúde emocional de quem presta cuidado.

Santos e Moreira ${ }^{(13)}$, após estudarem a questão da resiliência de profissionais de enfermagem que trabalham com crianças e adolescentes crônicos, incluindo o cuidado na finitude da vida, afirmaram que esse trabalho produz marcas no profissional de saúde, que o sofrimento e a morte dos pacientes precisam ser reconhecidos como parte do processo de trabalho e que é fundamental que a instituição, em sintonia com os princípios da Política Nacional de Humanização de Atenção e Gestão, acolha 
"a dor' dos profissionais, oferecendo suporte individual e coletivo.

$\mathrm{O}$ atendimento às demandas subjetivas do profissional de saúde requer das esferas assistenciais e gestoras uma escuta que busque compreender os sentidos das condutas e falas dos sujeitos. A elaboração simbólica e coletiva das estratégias de defesa auxilia no reconhecimento dos atores como membros do coletivo, contribui para a saúde física e mental, e amplia as relações de confiança e solidariedade ${ }^{(14)}$.

\section{CONCLUSÃO}

Consideramos que o minicurso atingiu o objetivo proposto, superando as expectativas acerca da representação de um espaço de diálogo para as questões intersubjetivas presentes no âmbito assistencial.

A metodologia ativa utilizada permitiu que as percepções fossem colocadas a partir das trocas de experiências de forma leve e humanitária, fugindo do padrão de uma palestra convencional. As vivências compartilhadas emergiram principalmente de questões relacionadas ao processo de morte, salientando a importância da discussão da temática neste cenário de atuação. Embora tenha sido demonstrado extremamente válido, o apoio institucional a estes profissionais não ocorre de forma sistemática, o que mostra fragilidade nos serviços de saúde.

Dores e conflitos foram demonstrados pelos participantes, principalmente no momento do compartilhamento de episódios marcantes da sua prática profissional, que envolvesse a subjetividade dele, do outro, ou a de ambos. Este episódio causou nas organizadoras do minicurso e autoras deste estudo imensa satisfação e contentamento. Foi possível sentir e compartilhar juntamente com os demais integrantes emoções e situações igualmente vivenciadas. Importa ressaltar que neste momento não houve julgamento ou timidez, mas apenas uma necessidade de dividir aflições e inquietações.

A validação das angústias desses profissionais auxiliou na problematização do cotidiano profissional e uniu o conhecimento e o desenvolvimento pessoal. Neste contexto, foram discutidos os ofícios, as experiências, o conhecimento técnico-científico, o senso comum e os afetos, permitindo uma articulação para reflexão e transformação da realidade.

O minicurso reforçou a ideia de que um espaço para partilhar emoções entre os profissionais que estão na linha de frente do cuidado é fundamental para que os mesmos não adoeçam, contribuindo para o aprimoramento da assistência.

É preciso haver ainda, de forma cotidiana, uma reflexão pessoal sobre os caminhos profissionais almejados e traçados, buscando o sentido do trabalho para a vida. Esta atenção reflete na prática profissional e permite um olhar sensível para o paciente, família, companheiros de trabalho e, acima de tudo, remete à uma autoavaliação, tão necessária para o sucesso das atividades desenvolvidas.

Esperamos que este minicurso, ainda que de forma incipiente, possa ter servido de base para a implementação de estratégias que favoreçam o estabelecimento de espaços onde os profissionais busquem dividir e compartilhar suas experiências de forma frequente e cotidiana. Que estes encontros sejam valorizados e inseridos na rotina de trabalho, sendo reconhecidos como primordiais à prática assistencial de toda a equipe de saúde.

\section{Referências}

1. Mello DF, Wernet M, Veríssimo MLÓR, Tonete VLP. Nursing care in early childhood: contributions from intersubjective recognition. Rev Bras Enferm [Internet]. 2017;70(2):446-50. DOI: http://dx.doi.org/10.1590/0034-71672016-0319.

2. Mehry EE. Saúde: cartografia do trabalho vivo. São Paulo: Hucitec; 2002. 3. Foucault M. Em defesa da sociedade. São Paulo: Martins Fontes; 1999.

4. Sá MC, Azevedo CS. Subjetividade e Gestão: explorando as articulações psicossociais no trabalho gerencial e no trabalho em saúde. In: AZEVEDO, CS (org). Subjetividade, gestão e cuidado em saúde: abordagens da psicossociologia. Rio de Janeiro: Editora Fiocruz; 2013. p. 33-50

5. Agra G, Formiga N, Sousa A, Soares M, Oliveira S, Costa M. Reflexões heideggereanas sobre o cuidar de enfermagem ao paciente com ferida neoplásica. Journal of Aging \& Innovation [Internet]. 2018 [acesso em 08 jun 2020]; 7(1):89-102. Disponível em: http://www.journalofagingandinnovation.org/ wp-content/uploads/9-reflex-fenomenol\%C3\%B3gicas.pdf.

6. Mota AS, Silva ALA, Souza AC. Educação permanente: práticas e processos da enfermagem em saúde mental. Revista portuguesa de enfermagem de saúde mental [Internet]. 2016 [acesso em 08 jun 2020]; especial(4):9-16. Disponivel em: http://www.scielo.mec.pt/pdf/rpesm/nspe4/ nspe4a02.pdf.

7. Mitre SM, Batista RS, Mendonça JMG, Pinto NMM, Meirelles CAB, Porto CPP, Moreira T, Hoffmann LMA. Metodologias ativas de ensino-aprendizagem na formação profissional em saúde: debates atuais. Ciência \& Saúde
Coletiva [Internet]. 2008 [acesso em 08 jun 2020]; 13(Sup2):2133-2144.

Disponível em: https://www.scielo.br/pdf/csc/v13s2/v13s2a18.pdf.

8. Souza EFD, Silva AG, Silva AILF. Active methodologies for graduation in nursing: focus on the health care of older adults. Rev Bras Enferm [Internet]. 2018; 71(suppl 2):920-4. DOI: http://dx.doi.org/10.1590/0034-7167-20170150.

9. Pitta A. Hospital: dor e morte como ofício. São Paulo: Hucitec; 2003.

10. Souza FF, Reis FP. 0 enfermeiro em face ao processo de morte do paciente pediátrico. J Health Biol Sci [Internet]. 2019; 7(3):277-283. DOI:10.12662/ 2317-3076jhbs.v7i3.2235.

11. Figueiredo LC. A metapsicologia do cuidado. In: As diversas faces do cuidar: novos ensaios de psicanálise contemporânea. São Paulo: Escuta; 2014. p. 131-151.

12. Winnicott DW. Distorções do ego em termos de verdadeiro e falso self. In D. W. Winnicott. 0 ambiente e os processos de maturação (pp. 128-139). Porto Alegre: Artes Médicas; 1960.

13. Santos RA, Moreira MCN. Resiliência e morte: o profissional de enfermagem frente ao cuidado de crianças e adolescentes no processo de finitude da vida. Cien Saude Colet [Internet]. 2013 Nov [acesso em 08 jun 2020]. Disponível em: http://www.scielo.br/scielo.php?pi$d=S 1413-81232014001204869 \&$ script=sci_arttext\&tlng=pt.

14. Dejours C. Psicodinâmica do trabalho: casos clínicos. Porto Alegre/São Paulo: Dublinense; 2017. 